\title{
Socio-Economic Conditions of Gujjars in South Kashmir Their Challenges and Strategies
}

\author{
Aasif Ali Naikoo, Shashank Shekhar Thakur, Tariq Ahmad Guroo \\ Department of Sociology and Social Work, \\ Barkatullah University Bhopal 462026 (MP), INDIA
}

\begin{abstract}
Kashmir Valley is known as place where people are embraced with multicultural and multilingual atmosphere. Gujjars are the tribal group mostly residing on hilly and mountainous regions of Valley with different traditions, rituals and language. They are economically poor, socially backward, but culturally stable. Their economic profile is poor than the general population of region. They are suffering from so many issues in their day today life. Their housing, sanitation, Education, electricity, health care facilities are very low sub-standard than different sections of population, Also Government has not provided them the basic assets to eradicate the tribal poverty. The literacy rate among Gujjars of south Kashmir is also very low. This paper is based on both primary and secondary data and tries to analyze the magnitude of socio-economic conditions of different parameters and also this paper contains some suggestions, which needs to be implement on the ground level in order to eradicate their socio economic problems.
\end{abstract}

KEYWORDS: Gujjars, Poverty, Backward, Illiteracy and Economy.

Introduction of Gujjars in Kashmir: Gujjars are the pastoral agricultural ethinic and linguistic group with populations in India, Pakistan and a small number in northern Afghanistan. Gujjars have their unique language known as Gujjari. Gujjars are categorized as other backward classes (OBC) in some starts of India however Gujjars in J\&k and parts of Himachal Pradesh are categorised as schedule tribes. It is assumed that Gujjars came to Jammu \& Kashmir from Gujarat (via Kashmir) and hazara region of Khyber pakhtunkhwa. According to 2011 census $99.3 \%$ of Gujjars in J\&K are the followers of Islam. The Gujjar tribe is essentially a

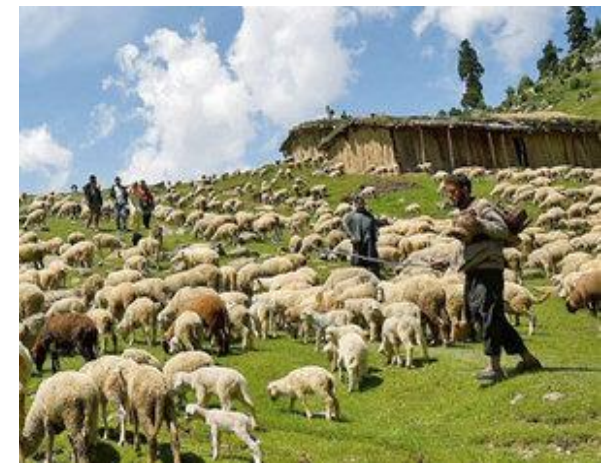
nomadic community permanently settled in colonies, taking to farming, businesses and joining government jobs on small scale. Inter marriages freely take place among them. The houses of the Gujjars are locally known as "kothas". It is generally a mud-house against the slope of a hillock. So for as the dress is concerned, the males wear a long shirt and a trouser as per the doctrines of Islam. Also they wear a turban of a peculiar style. The ladies usually wear a long shirt and shalwar with a cap or dupatta on their head. Gujjars are mostly vegetarians. The usual dishes of Gujjars are Daal, Maki ki Roti, Sarsoo ka Saag and products of Milk. They have their own cattles, they look after them and sell them at different times to earn their livelihood. Gujjars are the great followers of their culture and culture plays a great role in their day today life. 
Methodology: The data for the present paper was collected from the four districts of south Kashmir on the basis of random sampling method. Among these four districts 200 respondents were taken for study purpose 50 respondents from each district through random sampling method to analyze the socio-economic conditions of Gujjars of south Kashmir. The major research techniques involved were interview method with a well structured interview schedule. It helped us to collect the deeper and real social facts of Gujjars. It also helped us to understand the every aspect of socio-economic and cultural life of such tribes. To get the exact information at the ground level we also conducted open and close end interviews. The close end interviews were based on properly formulated interview schedule and the data recorded was then analyzed carefully and formally written down.

\section{Profile of Respondents:}

Table 1 Distribution of Respondents

\begin{tabular}{|l|l|l|l|l|l|l|l|l|l|}
\hline Districts selected & \multicolumn{2}{l|}{ Gender } & \multicolumn{2}{l|}{ Marital status } & \multicolumn{2}{l|}{ Educational status } & \multicolumn{2}{l|}{ Age status } \\
\cline { 2 - 10 } & M & F & M & Um & Lit & Illit & $\begin{array}{l}15- \\
25\end{array}$ & $\begin{array}{l}25- \\
35\end{array}$ & $\begin{array}{l}35- \\
\text { above }\end{array}$ \\
\hline Anantnag & 20 & 30 & 30 & 20 & 20 & 30 & 15 & 30 & 05 \\
\hline Kulgam & 35 & 15 & 43 & 07 & 22 & 28 & 18 & 12 & 20 \\
\hline Pulwama & 40 & 10 & 30 & 20 & 15 & 35 & 10 & 20 & 20 \\
\hline Shopian & 20 & 30 & 27 & 23 & 17 & 33 & 05 & 15 & 30 \\
\hline Total & 115 & 85 & 130 & 70 & 74 & 126 & 48 & 77 & 75 \\
\hline
\end{tabular}

Note: $\mathrm{M}=$ male, $\mathrm{F}=$ female, $\mathrm{M}=$ married, $\mathrm{Um}=$ unmarried, Lit=literate \& Ilit=illiterate

Table 1 is the profile of 200 respondents selected from the 4 districts of south Kashmir such as: Anantnag, Kulgam, Pulwama and Shopian, from each district we have taken 50 respondents for the current study, on the basis of Gender wise distribution among these 200 respondents 115 are males and 85 are females. On the basis of marital status among these 200 respondents 130 are married and 70 are unmarried. On the basis of Educational status among these 200 respondents 74 are literate and 126 are illiterate. The table also shows out of 200 respondents 48 respondents are in the age group of (15-25), 77 are in the age group of (25-35) and 75 are in the age group of (35above).

\section{Research Objectives:}

The research problem has focused on the following proposed objectives.

- To know about the socio-economic life of the Gujjars.

- To know about the sources available for their income.

- To know about the facilities provided by the government.

- To know the culture and its importance among Gujjars.

Data Analysis: Data collected from the field is analysed in the tables below which determines the socio economic conditions of Gujjars of south Kashmir. 
TABLE 2.1 TYPE OF HOUSE

\begin{tabular}{|c|c|c|c|c|c|}
\hline \multirow{2}{*}{$\begin{array}{l}\text { Type of } \\
\text { houses }\end{array}$} & \multicolumn{4}{|c|}{ No. of respondents district wise } & \multirow[t]{2}{*}{ Percentage } \\
\hline & Anantnag & Kulgam & Pulwama & Shopian & \\
\hline Pacca & 0 & 2 & 0 & 1 & $1.5 \%$ \\
\hline $\begin{array}{l}\text { Semi- } \\
\text { pacca }\end{array}$ & 05 & 08 & 07 & 03 & $11.5 \%$ \\
\hline katcha & 45 & 40 & 43 & 46 & $87 \%$ \\
\hline Total & 50 & 50 & 50 & 50 & $100 \%$ \\
\hline
\end{tabular}

This table reveals that $11.5 \%$ of the respondents live in semi-pacca houses, $87 \%$ live in katcha houses and $1.5 \%$ live in a pucca houses. This means that they don't have proper housing facilities, they are mostly poor and they are not able to afford pacca house.

\section{TABLE 2.2 LEVEL OF SATISFACTION FROM HOUSING}

\begin{tabular}{|l|l|l|l|l|l|}
\hline \multirow{2}{*}{ RESPONSE } & \multicolumn{4}{|l|}{ NO. OF RESPONDANTS DISTRICT WISE } & \multirow{2}{*}{ PERCENTAGE } \\
\cline { 2 - 5 } & Anantnag & Kulgam & Pulwama & Shopian & \\
\hline Highly satisfied & 1 & 2 & 1 & 2 & $03 \%$ \\
\hline Satisfied & 15 & 20 & 17 & 18 & $35 \%$ \\
\hline Unsatisfied & 34 & 28 & 32 & 30 & $62 \%$ \\
& & & & & \\
\hline Total & 50 & 50 & 50 & 50 & $100 \%$ \\
& & & & & \\
\hline
\end{tabular}

This table reveals that $35 \%$ of the respondents are satisfied and $62 \%$ of the respondents are unsatisfied with their housing conditions and only $3 \%$ respondents were highly satisfied with their housing conditions. In this study the area of the study was completely tribal. $90 \%$ of the respondents didn't have any toilet facility, they go in open for toilet purposes which shows that they are very backward in such modern times. All the respondents said that they use wood for cooking purposes as they can't afford a gas connection. 
Table 2.3 Proper water supply

\begin{tabular}{|l|l|l|l|}
\hline $\begin{array}{c}\text { Name of the } \\
\text { District }\end{array}$ & $\begin{array}{c}\text { Total no. of respondents } \\
\text { taken from each district }\end{array}$ & Yes & No \\
\hline Anantnag & 50 & 30 & 20 \\
\hline Kulgam & 50 & 17 & 33 \\
\hline Pulwama & 50 & 25 & 25 \\
\hline Shopian & 50 & 20 & 30 \\
\hline Total & 200 & 92 & 108 \\
\hline
\end{tabular}

The above table reveals that $46 \%$ respondents said that they have proper water facility in their area and $54 \%$ respondents said that they don't have proper water facility in their area. This means that maximum respondents don't have proper water facility. Gujjars from District Anantnag and Kulgam revealed that they still have to cover longer distances to collect water for their daily use and drinking purposes and it creates lot of difficulties for them. Gujjars from all districts also complained about proper electricity.

TABLE 2.4 AVALABILITY OF HEALTH CENTERS

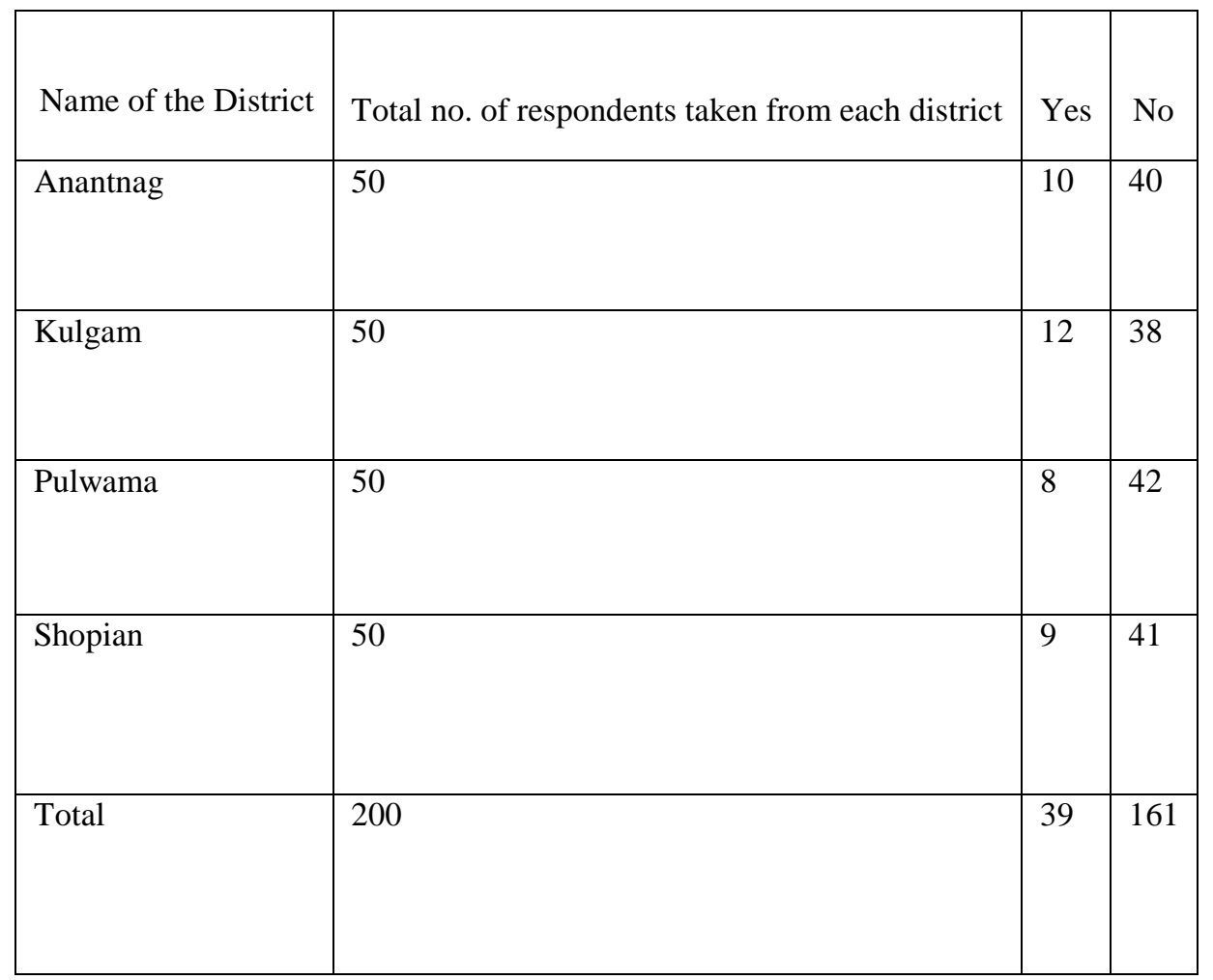

The above table 2.4 reveals that only $19.5 \%$ respondents have health facility in their area and $80.5 \%$ did not have health facility in their area. The tribes of Kulgam and shopian district are still facing so many problems and they have to travel lot of distance to reach the hospital. They said 
that price of food items nowadays is very high and as such they can't buy all food items from the market. Moreover they cannot afford to buy all essential food items for their family because of their low income.

Table 2.5 Cultivating land of own

\begin{tabular}{|l|l|l|l|}
\hline $\begin{array}{c}\text { Name of the } \\
\text { district }\end{array}$ & $\begin{array}{l}\text { Total no. of respondents } \\
\text { taken from each district }\end{array}$ & Yes & No \\
\hline Anantnag & 50 & 40 & 10 \\
\hline Kulgam & 50 & 35 & 15 \\
\hline Pulwama & 50 & 40 & 10 \\
\hline Shopian & 50 & 30 & 20 \\
\hline Total & 200 & & \\
\hline
\end{tabular}

Table 2.5 reveals that $25 \%$ people have their own land for cultivation and remaining $75 \%$ people have no land of their own for cultivation and use land of others for cultivation .Gujjars of south Kashmir also narrated that Government have not provided them basic tools like proper fertilizers, pests, fungisides and proper irrigation facility, they also commented that rain and hail stones damaged our crop from last few years which have become a big burden on their economy.

Table 2.6 income status

\begin{tabular}{|c|c|c|c|c|c|}
\hline \multirow[t]{2}{*}{ income } & \multicolumn{4}{|c|}{ No. of responses district wise } & \multirow[t]{2}{*}{ Percentage } \\
\hline & Anantnag & Kulgam & Pulwama & Shopian & \\
\hline $1000-5000$ & 35 & 37 & 33 & 40 & $72.5 \%$ \\
\hline $5000-10000$ & 10 & 12 & 14 & 5 & $20.5 \%$ \\
\hline $10000-15000$ & 4 & 1 & 2 & 3 & $05 \%$ \\
\hline $15000-20000$ & 1 & 0 & 1 & 2 & $02 \%$ \\
\hline Total & 50 & 50 & 50 & 50 & $100 \%$ \\
\hline
\end{tabular}


Table 2.6 indicates that $72.5 \%$ population is having income between $1000-5000,20.5 \%$ population is having income between 5000-10000, 5\% population comes under income level between 1000015000 and only $2 \%$ population is having income level between $15000-20000$. The study reveals that most of the population comes under the income level of 1000-5000 which indicates the condition of Gujjars is not as developed as it should be.

Table 2.7 Conditions of schools

\begin{tabular}{|c|c|c|c|c|c|}
\hline \multirow[t]{2}{*}{ Responses } & \multicolumn{4}{|c|}{ No. of responses District wise } & \multirow[t]{2}{*}{ Percentage } \\
\hline & Anantnag & Kulgam & Pulwama & Shopian & \\
\hline Good & 10 & 15 & 20 & 7 & $26 \%$ \\
\hline $\mathrm{Bad}$ & 20 & 5 & 3 & 10 & $19 \%$ \\
\hline Worst & 2 & 5 & 2 & 11 & $10 \%$ \\
\hline Satisfactory & 18 & 25 & 25 & 22 & $45 \%$ \\
\hline Total & 50 & 50 & 50 & 50 & $100 \%$ \\
\hline
\end{tabular}

Table 2.7 indicates that $26 \%$ of respondents responded that the condition of schools are good, $19 \%$ of respondents responded about worst condition of schools and $45 \%$ people responded that the conditions of schools are satisfactory. Gujjars who resides in far flung areas were not able to send their children to school because the schools are very far from their locality and there are no means of transport system. Some of the respondents told that the seasonal teachers are not giving the proper attention towards the students.

Table 2.8 Type of family system

\begin{tabular}{|c|c|c|c|c|c|}
\hline \multirow{2}{*}{$\begin{array}{l}\text { Type of } \\
\text { family } \\
\text { system }\end{array}$} & \multicolumn{4}{|c|}{ No. of responses District wise } & \multirow[t]{2}{*}{ percentage } \\
\hline & Anantnag & Kulgam & Pulwama & Shopian & \\
\hline Joint family & 40 & 35 & 38 & 27 & $70 \%$ \\
\hline $\begin{array}{l}\text { Nuclear } \\
\text { Family }\end{array}$ & 10 & 15 & 12 & 23 & $30 \%$ \\
\hline others & 0 & 0 & 0 & 0 & $0 \%$ \\
\hline Total & 50 & 50 & 50 & 50 & $100 \%$ \\
\hline
\end{tabular}

Table 2.8 indicates that $70 \%$ of families live as joint families and only $30 \%$ of families are living as nuclear families. It indicates that the Gujjars follow the the old tradition and they are bind with their culture because culture plays important role in their day today life. They live together and work together as a unit to save expenditures and it controls their work pressure. 
Table 2.9 Age of Marriage

\begin{tabular}{|l|l|l|l|l|l|}
\hline \multirow{2}{*}{$\begin{array}{c}\text { Age } \\
\text { Group }\end{array}$} & \multicolumn{5}{|c|}{ No. Of Responses District Wise } \\
\cline { 2 - 6 } & Anantnag & Kulgam & Pulwama & Shopian & Total \\
\hline $10-15$ & 9 & 7 & 5 & 6 & $13.5 \%$ \\
\hline $15-20$ & 30 & 33 & 35 & 30 & $64 \%$ \\
\hline $20-25$ & 11 & 8 & 10 & 10 & $19.5 \%$ \\
\hline $25-30$ & 0 & 2 & 0 & 4 & $03 \%$ \\
\hline Total & 50 & 50 & 50 & 50 & $100 \%$ \\
\hline
\end{tabular}

Table 2.9 indicates that $13.5 \%$ marriages are held in the age group of $10-15,64 \%$ marriages are held in the age group of $15-20,19.5 \%$ marriages are held in the age group of $20-25$ and only $3 \%$ marriages are held in the age group of 25-30. It indicates that the Gujjars still follow the child marriage and early marriage system and most of them believe in arrange marriage.

\section{SOCIO-ECONOMIC CONDITIONS OF GUJJARS IN SOUTH KASHMIR}

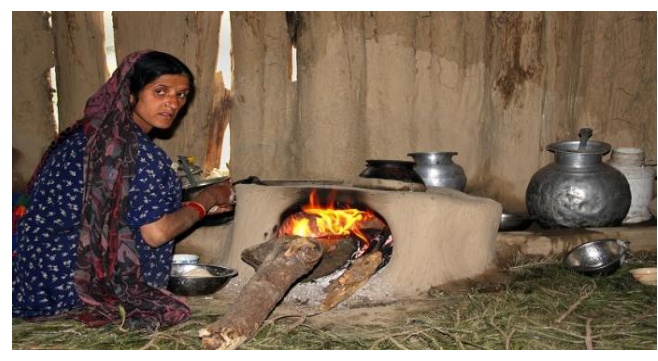

A large number of Gujjars reside in the south Kashmir. The percentage of literacy among Gujjars in the study area is very low. The Gujjars of this area reside in far-flung areas and are suffering from various socio-economic problems like as, having no road links, Child labour, Low percentage of literacy among Gujjar woman, Unemployment in educated Gujjar youths, less opportunities of coaching for admission in professional and technical institutions, Poor economic conditions, Shortage of educational institutions in Gujjar localities, Malfunctioning of mobile schools, Lack of proper marketing facilities of wood, milk and matter, Lack of financial resources, Non availability of work to Gujjar labourers, unavailability of hospitals and other health centers, Lack of proper transport system, lack of proper irrigation facility, improper functioning of animal husbandry department and unavailability of modern agricultural tools

\section{Challenges:}

The Gujjars of south Kashmir are facing so many challenges in there day today life. Government have not provided them the basic facilities for the upliftment of social as well as economic status
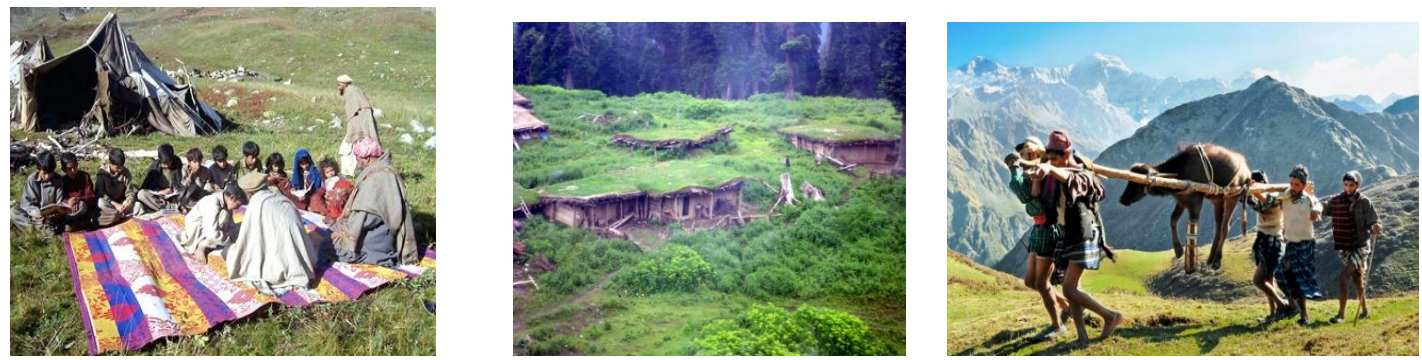

http://dx.doi.org/10.19085/journal.sijbpg050401 
of people. Large number of population is still facing so many deprivations by the government and other private organizations. Educational organizations are not functioning properly which keeps them away from this field. Schools are not located at proper location which is a big burden for the present Gujjar population. The people are not aware about the tribal schemes or any other government implemented schemes which also keep them away from the development. There is not any proper irrigation facility when the whole population is dependent on agricultural activities and also they have to bring the drinking water from a long distance which becomes a heavy load on women folk. Most of the places are still suffering due to lack of electricity and government has not provided them any subsidy based gas connections, which makes their life so miserable.

\section{Suggestions:}

i. Road connectivity and Transport system should be provided so that they remain connected with nearby towns.

ii. Agricultural tools and proper use of fertilizers should be provided by the government.

iii. Gas chulaas should be provided by the government on subsidy basis.

iv. There should be regular surveys by govt. to check out their problems.

v. NGOS should play the major role in all departments of village awareness.

vi. There should be proper location of educational institutions.

vii. Animal husbandry should work properly to aware them about cattle management.

viii. Drinking water facilities should be provided by the government.

ix. Government should provide them the cattle related business units.

Conclusion: On the whole it has been observed that Gujjars of south Kashmir have so many miseries and their life is not as comfortable as it should be. The poverty rates of Gujjars are more than the general population. All these scheduled tribe Gujjars are socially and economically deprived and have not basic amenities of life. Their agricultural facilities are also poor due to lack of agricultural facilities like (irrigation, proper fertilizers, insecticides and pesticides). They do not have proper means of health centers and transportation. Gujjars are also backward in means of education and there is a large number of child labour. Gujjars live in kaccha houses because they can't afford pacca houses. They do not have any proper source of income. It needs a great concern to eradicate their social and economic problems so that they can live a quality life.

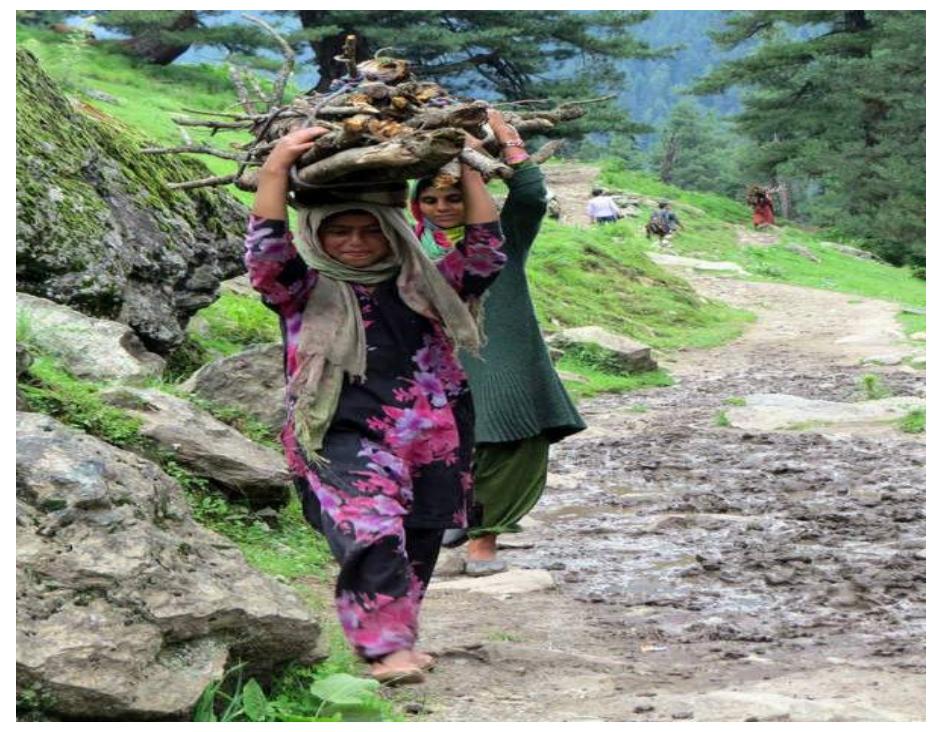




\section{References:}

[1]. Azharu Ud Din (2015), Socio-Economic Conditions Of Gujjar And Bakerwal Tribes Of Kashmir, International Journal Of Recent Research In Social Sciences And Humanities (IJRRSSH), Vol 2, Issue 2, Pp 115-120.

[2]. Bhalla, S.S. (2003) 'Recounting The Poor, Poverty In India 1983-1999.' Economic \& Political Weekly 38(4), Pp 25-31.

[3]. Kannan, K.P. (2010) 'Estimating And Identifying The Poor.' Journal Of Human Development 4(1), Pp91- 98.

[4]. Mohd. Tufail (2014), Demography, Social And Cultural Characteristics Of The Gujjars And Bakarwals, A Case Study Of Jammu And Kashmir, IOSR Journal Of Humanities And Social Science (IOSR-JHSS), Vol 19,Issue ,Pp 24-36.

[5]. Ruhi Rafiq (2014), Socio-Economic Profile Of Dodhi Gujjars In Jammu And Kashmir, IRC'S International Journal Of Multidisciplinary Research In Social And Management Sciences, Vol 2 Issue 3, Pp 81-88.

[6]. S. Gupta And F.B. Beg, (2012), "Socio Economic Upliftment Of Gujjars In Jammu And Kashmir" International Journal Of Research In Commerce, Economics And Management, Vol-2, Pp 162-66.

[7]. Salil Basu, (2006) "Dimensions Of Tribal Health In India", Health And Population-Prospective And Issues, Vol. 23, No. 2, Pp 61-70.

[8]. Showkeen Bilal Ahmad Gul, (2014), Assessment And Understanding Of Gujjar And Bakerwal Women's Health In Jammu And Kashmir, Journal Of Business Management \& Social Sciences Research ( JBM\&SSR ) Vol 3,No.3 ,Pp 37-42.

[9]. Virender Koundal, (2012), "Socio-Economic Conditions Of Nomadic Gujjars Women In Udhampur District Of Jammu And Kashmir” International Journal Of Social Science Tomorrow, Vol.1 No. 3 Pp 16

[10].Virender Koundal,(2012), Poverty Among Nomadic Gujjars- A Case Study Of J \& K And H.P International Journal Of Marketing, Financial Services \& Management Research Vol.1 Issue 8, Pp 206230.

[11].Vivak Sharma (2017), A Study Of Educational Status Of Tribal Gujjar Children Of Vijaypur Block In Samba District Of Jammu And Kashmir, International Journal For Innovative Research In Multidisciplinary Field, Vol 3, Issue 7, Pp 573-579. 